\title{
Carmen María Pujante Segura: La novela corta contemporánea (desde mediados del siglo XX hasta hoy a través de Ayala, Vila-Matas y Barba). Madrid: Visor, 2019.
}

La novela corta contemporánea es una obra que se establece como la última aportación hasta la fecha en la labor investigadora de Carmen María Pujante Segura, experta en este género que lleva recorrida una trayectoria ya destacable con diferentes artículos y, principalmente, el libro De la novela corta y la nouvelle (1900-1950) — reseñado también en Lejana-. ${ }^{1}$ El objeto de esta reseña, obra editada por Visor en 2019, se establece, entonces, como una continuación del anterior libro de 2014, pues el foco de atención pasa a estar en la novela corta hispánica de la segunda mitad del siglo XX y de principios del siglo XXI. Tratándose de un estudio sistemático de este género, aunque acotado a unas coordenadas espaciotemporales determinadas, con él consigue Pujante Segura contribuir a este campo de estudio que se encuentra yermo frente al de otros géneros narrativos, salvo por valiosas excepciones, como son el grupo de investigación de la Universidad Nacional Autónoma de México que ha derivado en la creación de una biblioteca virtual de novela corta y estudios sobre este género, ${ }^{2}$ la celebración de un coloquio internacional sobre la novela corta moderna en el mundo hispánico en 2018 en la Universidad Eötvös Loránd de Budapest o la publicación en esta misma revista del número especial "La novela corta revisitada" en 2020. ${ }^{3}$

Ante el desinterés investigador generalizado sobre este género y frente a la producción literaria ingente del mismo en las últimas décadas que la autora observa, ella parte de las fuentes clásicas y hace un esbozo de las principales aportaciones de la crítica para abordar el desarrollo reciente de la novela corta en España, detallando y explicando las características de este género en su configuración más reciente. Asimismo, al estudio de la novela corta desde 1950 hasta nuestros días añade el análisis del cultivo de este género por parte de Francisco Ayala, Enrique Vila-Matas y Andrés Barba, así como de sus aportaciones teóricas, pues son escritores que reflexionan sobre el género, al igual que hicieron Mario Benedetti o Ricardo Piglia. La elección de estos tres autores está debidamente justificada: son escritores y teóricos de la narrativa breve cuya obra literaria muestra aspectos que la autora analiza en su estudio histórico y teórico de la novela corta. Se trata de una obra de dicho carácter porque analiza, por un lado, el lugar que la novela corta ocupa en las historias de la literatura española y los medios editoriales en que esta se publica y, por otro, plantea el problema terminológico inherente a este género, del que establece cuáles son sus características formales y estructurales intrínsecas para posteriormente analizar de qué modo se dan en la obra de los tres autores seleccionados. Además de compaginar esta doble metodología, la obra incurre en una apertura a otros campos de estudio, como el recueil o los ciclos, en tanto que son (macro)géneros que pueden albergar novelas cortas (y/o cuentos).

Tras un primer sondeo del estado de la cuestión en que se encuentra el estudio de la novela corta, Pujante Segura se adentra en la historia de la literatura española contemporánea

\footnotetext{
${ }^{1}$ KÜRTHY, Ádám András: "Reseña de Carmen María Pujante Segura: De la novela corta y la nouvelle (19001950). Estudio comparativo entre escritoras", Lejana. Revista Crítica de Narrativa Breve, 12 (2019): 69-71. Disponible en: http://ojs.elte.hu/index.php/lejana/article/view/398. https://doi.org/10.24029/lejana.2019.12.398.

${ }^{2}$ www.lanovelacorta.com.

${ }^{3}$ http://ojs.elte.hu/index.php/lejana/issue/view/34. DOI: https://doi.org/10.24029/lejana.2020.13.
} 
para rastrear la presencia de la novela corta en este tipo de manuales. Un acertado recorrido por las principales historias de la novela y del cuento y reseñas de críticos que inciden en el género de la obra literaria que analizan conduce a la autora a afirmar que aún queda por trazar la evolución de la novela corta desde el siglo XX hasta el XXI, etapa para la que adquiere relevancia la novela corta cultivada por los escritores españoles exiliados y su relación con la obra cervantina. De los diferentes términos que en el ámbito hispánico se utilizan para denominar este género — novela corta, novela breve o incluso nouvelle y novella —, Pujante Segura trae a colación las propuestas de Ayala, Vila-Matas y Barba para sus propias obras. Tal cuestión terminológica está ligada a la cuestión editorial, pues para el estudio de la novela corta se hace necesaria la perspectiva extratextual o sociológica al ser sus características hasta cierto punto dependientes del medio en que se publica. En el período acotado, el peso de las plataformas editoriales va variando, de las colecciones - El Cuento Semanal, La Novela del Sábado, La Novela Popular, etc. — o series de novelas cortas a premios dedicados a este género, la inclusión de estos relatos en distintos volúmenes recopilatorios (recopilaciones, ciclos, etc.) y la publicación de novelas cortas de forma suelta o exenta, aunque esta última práctica es inusual. El fenómeno de la recopilación con sus diferentes variantes, cuya tendencia es acusada en el siglo XX, lo aplica Pujante Segura para explicar también la obra de Ayala, Vila-Matas y Barba.

Este primer planteamiento de cariz histórico desemboca en otro más teórico y genológico, como veníamos anunciando. Este libro ofrece una síntesis de las principales aportaciones teórico-críticas sobre la novela corta y una serie de características que son propias de este género tal y como se ha desarrollado en España desde 1950; para ello, la autora se apoya en las contribuciones de destacados estudiosos como Leibowitz, Scholz, Piglia, Pabst, etc. y en los textos literarios de Ayala, Vila-Matas, Barba y otros escritores a modo de ejemplo para ilustrar sus ideas. El capítulo sobre las características de la novela corta contemporánea está dividido en diferentes apartados: extensión, narración, descripción y diálogo, tiempos, espacios, tratamientos temáticos, personajes y experimentalidad e intergeneridad. Todos ellos están imbricados y condicionados tanto por la extensión como por el medio de publicación y edición y, como la autora señala, no son aspectos exclusivos de la novela corta, sino que "las funciones asumidas por cada uno de ellos configuran su idiosincrasia genérica" (2019: 117).

Desde un prisma analítico se van a estudiar las obras de Ayala, Vila-Matas y Barba que pueden ser catalogadas de novelas cortas, como son El rapto - la novela corta por antonomasia de Ayala_- "Chet Baker piensa en su arte" — nouvelle y/o ficción crítica que da título a la recopilación antológica de Vila-Matas-, y las nouvelles que componen La recta intención de Barba. Pese a que la atención de la autora esté centrada en estas tres obras que ha seleccionado, no deja de mencionar otras que también son novelas cortas. ${ }^{4}$ De Ayala, que escribió novelas cortas sobre todo durante su exilio, además de subrayar y analizar algunos puentes trazados entre su obra y las Novelas ejemplares, recoge y estudia sus ideas sobre la novela corta que están dispersas en sus ensayos literarios centrados más en la novela, el

\footnotetext{
${ }^{4}$ Las reunidas en la primera edición de La cabeza del cordero, "Historia de macacos", "El as de Bastos" y los dos relatos incluidos en Cazador en el alba de Ayala; La asesina ilustrada, "El hijo del columpio" y la primera parte de El mal de Montano de Vila-Matas; El hueso que más duele, La hermana de Katia, Las manos pequeñas, Muerte de un caballo y las que componen Ha dejado de llover de Barba.
} 
cuento y Cervantes, a quien consideraba el creador de la novela (corta) moderna por haber escrito no el Quijote, sino las Novelas ejemplares. Al tener en cuenta la obra de Vila-Matas anterior a "Chet Baker piensa en su arte", Pujante Segura descubre una red tejida entre sus relatos, pues desembocan en este texto híbrido que forma parte de una recopilación antológica, siendo el único inédito y el más extenso, colocado en penúltimo lugar a modo de cierre. El análisis de la adscripción discursiva y los recursos temático-constructivos llevan a la autora a considerar que se trata de una recopilación cohesionada, sin llegar a conformar un ciclo, que va más allá de una mera yuxtaposición antológica de textos. También de Barba analiza La recta intención desde esa perspectiva genérica de los ciclos o recueils, pero además de examinar la obra en su conjunto, como un todo, se centra en las partes que la componen, que son cuatro novelas cortas. Pujante Segura había publicado anteriormente estudios centrados en algunas de las obras de Barba, y ello la lleva a afirmar que la obra de este autor presenta una evolución a través de nouvelles y novelas breves.

En definitiva, La novela corta contemporánea (desde mediados del siglo XX hasta hoy a través de Ayala, Vila-Matas y Barba) augura un largo y prometedor recorrido en las investigaciones de la novela corta, ya que ha iniciado un análisis de conjunto de las novelas cortas y las aproximaciones críticas a las mismas que aparecen desde 1950. La propia autora señala que aún hay tareas y debates pendientes, como incluir la novela corta en el lugar que le corresponde en la historia de la literatura española, confeccionar un canon o elenco para confirmar la tradición de la novela corta española, etc. La autora sigue emprendiendo este camino al haber coordinado el último número de Ínsula, publicado en junio de 2020, un monográfico dedicado a la novela corta en el mundo hispánico desde $1940 ;{ }^{5}$ este número y el libro reseñado constituyen destacadas y valiosas contribuciones de Carmen María Pujante Segura al campo investigador de la novela corta.

Sandra Mendoza Vera

Universidad de Murcia sandra.mendoza@um.es

DOI: https://doi.org/10.24029/lejana.2020.14.1675

Recibido: el 30 de julio de 2020

Aceptado: el 26 de octubre de 2020

Publicado: el 26 de febrero de 2021

(C) Sandra Mendoza Vera

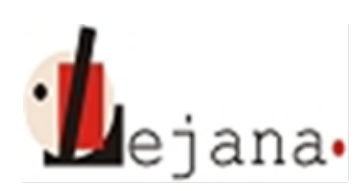

http://ojs.elte.hu/index.php/lejana

Universidad Eötvös Loránd, Departamento de Español, 1088 Budapest, Múzeum krt. 4/C

\footnotetext{
${ }^{5}$ https://www.insula.es/revista/la-novela-corta-en-el-mundo-hispanico-desde-1940-problemas-y-estrategias.
} 